\title{
Ultrafast Excited-State Decay Mechanisms of 6-Thioguanine Followed by Sub-20 fs UV Transient Absorption Spectroscopy
}

\author{
Danielle C. Teles-Ferreira ${ }^{1}$, Cristian Manzoni ${ }^{2}{ }^{\mathbb{D}}$, Lara Martínez-Fernández $^{3}$, Giulio Cerullo ${ }^{2,4}{ }^{\oplus}$, \\ Ana Maria de Paula ${ }^{5}$ and Rocío Borrego-Varillas $2, *$ (i)
}

check for

updates

Citation: Teles-Ferreira, D.C.

Manzoni, C.; Martínez-Fernández, L.; Cerullo, G.; de Paula, A.M.;

Borrego-Varillas, R. Ultrafast Excited-State Decay Mechanisms of 6-Thioguanine Followed by Sub-20 fs UV Transient Absorption Spectroscopy. Molecules 2022, 27, 1200. https://doi.org/10.3390/ molecules 27041200

Academic Editor: Boiko Cohen

Received: 22 December 2021

Accepted: 2 February 2022

Published: 10 February 2022

Publisher's Note: MDPI stays neutral with regard to jurisdictional claims in published maps and institutional affiliations.

Copyright: (C) 2022 by the authors. Licensee MDPI, Basel, Switzerland. This article is an open access article distributed under the terms and conditions of the Creative Commons Attribution (CC BY) license (https:// creativecommons.org/licenses/by/ $4.0 /)$.
1 Instituto Federal de Minas Gerais, Campus Ouro Preto, Ouro Preto 35400-000, MG, Brazil; danielle.teles@ifmg.edu.br

2 Istituto di Fotonica e Nanotecnologie-Consiglio Nazionale delle Ricerche (IFN-CNR), Piazza Leonardo da Vinci 32, I-20133 Milano, Italy; cristian.manzoni@polimi.it (C.M.); giulio.cerullo@polimi.it (G.C.)

3 Departamento de Química, Facultad de Ciencias and Institute for Advanced Research in Chemistry (IADCHEM), Campus de Excelencia UAM-CSIC, Universidad Autónoma de Madrid, Cantoblanco, 28049 Madrid, Spain; lara.martinez@uam.es

4 Dipartimento di Fisica, Politecnico di Milano, Piazza Leonardo da Vinci 32, I-20133 Milano, Italy

5 Departamento de Física, Universidade Federal de Minas Gerais, Belo Horizonte 31270-901, MG, Brazil; ana@fisica.ufmg.br

* Correspondence: rocio.borrego@polimi.it

\begin{abstract}
Understanding the primary steps following UV photoexcitation in sulphur-substituted DNA bases (thiobases) is fundamental for developing new phototherapeutic drugs. However, the investigation of the excited-state dynamics in sub-100 fs time scales has been elusive until now due to technical challenges. Here, we track the ultrafast decay mechanisms that lead to the electron trapping in the triplet manifold for 6-thioguanine in an aqueous solution, using broadband transient absorption spectroscopy with a sub-20 fs temporal resolution. We obtain experimental evidence of the fast internal conversion from the $S_{2}\left(\pi \pi^{*}\right)$ to the $S_{1}\left(n \pi^{*}\right)$ states, which takes place in about $80 \mathrm{fs}$ and demonstrates that the $S_{1}\left(n \pi^{*}\right)$ state acts as a doorway to the triplet population in $522 \mathrm{fs}$. Our results are supported by MS-CASPT2 calculations, predicting a planar $S_{2}\left(\pi \pi^{*}\right)$ pseudo-minimum in agreement with the stimulated emission signal observed in the experiment.
\end{abstract}

Keywords: ultrafast spectroscopy; thiobases; global analysis

\section{Introduction}

In 1950, George Hitchings and Gertrude Elion [1] obtained, by exchanging oxygen with sulphur in nucleobases, a potent drug for the treatment of numerous diseases [2-5]. This discovery led them to be honoured with the Nobel Prize in 1988 in the category of Physiology and Medicine. Such nucleobase derivatives are known as thiobases, and there has been a great effort to unravel their energy deactivation pathways [6,7]. The sulphur substitution in the nucleobases causes noticeable changes in the photophysics of these molecules [8-19] in comparison with the canonical nucleobases. There is a redshift of the absorption spectrum and a loss of photostability when excited by ultraviolet (UV) light. Unlike the canonical bases, which quickly repopulate the ground state after UV photoexcitation via an internal conversion (IC) process mediated by conical intersections (CIs) $[20,21]$, the thiobases population mostly decays to a long-lived triplet state with a high quantum yield via an ultrafast intersystem crossing (ISC) process [12,22-24].

Due to the high transfer efficiency to the triplet states and, consequently, the high rate of singlet oxygen formation, several applications of the thiobases have been demonstrated. They are used as chemotherapeutic agents for the treatment of some types of skin cancer, as they enhance the polymerase chain reaction for DNA/RNA replication, they are used as chromophores for investigating specific interactions between nucleic acids and 
proteins [25-33]. In addition to their practical applications, they provide an excellent model system for understanding how a single atom substitution can modify the energy relaxation processes of canonical DNA/RNA nucleobases.

One of the open questions in the ultrafast dynamics of thiobases concerns the mechanism behind the efficient triplet manifold formation by ISC, which occurs shortly after the bright, excited singlet state is populated. In the literature, at least two hypotheses have been proposed: (i) the population of the triplet states mediated by a dark singlet state $[12,18,22,34-37]$ and (ii) the direct transition from the bright singlet state to the triplet states [12,18,22-24,34-36,38]. We have recently observed a third possibility: for watersolvated thiouracils, the triplet manifold is accessed by parallel channels. While part of the population decays directly from the photoexcited bright state, another part decays passing through a dark singlet state [36,39].

In the last few years, the process of triplet state formation by ISC in 6-thioguanine (6TG) has received considerable attention in the literature [6,18,23,40-45]. Time-resolved transient absorption and photoelectron spectroscopies have been applied both in solution and gas phase for the investigation of the ultrafast dynamics in time scales, ranging from hundreds of femtoseconds up to nanoseconds. However, the primary steps after UV photoexcitation are not experimentally documented, since technical challenges have long prevented access to the sub-100 fs time scale, a highly desired benchmark as these mechanisms determine the system response on longer time scales.

In this work, we investigate the ultrafast dynamics of buffered, solvated 6TG by means of broadband transient absorption spectroscopy (TAS) with sub-20 fs UV pump pulses. Thanks to our high temporal resolution, which exceeds by a one-order magnitude that of previous studies on this molecule, and the broad spectral probing window which extends from the UV to the visible range, we are able to obtain mechanistic insight regarding the ultrafast primary processes that lead to the formation of the triplet manifold and the time constants associated with it. In particular, we show that the internal conversion from $S_{2}\left(\pi \pi^{*}\right)$ to the $S_{1}\left(n \pi^{*}\right)$ state takes place in about $80 \mathrm{fs}$, with the $S_{1}\left(n \pi^{*}\right)$ acting as a doorway to the triplet population in approximately $500 \mathrm{fs}$. Therefore, our results demonstrate that the decay channel $S_{2}\left(\pi \pi^{*}\right) \rightarrow S_{1}\left(n \pi^{*}\right) \rightarrow T_{1}\left(\pi \pi^{*}\right)$, experimentally observed so far only in thiouracils [36,39], is more general and can also be found in purine thiobases.

\section{Results and Discussion}

Figure 1a shows the 6TG steady-state linear absorption spectrum (black) and the pump pulse spectrum used for the TAS measurements (blue), while Figure $1 \mathrm{~b}$ displays the emission spectrum. The lowest energy absorption band of 6TG presents a maximum at $340 \mathrm{~nm}$ (Figure 1a, black curve). Several studies $[43,46,47]$ have assigned this band to the $\mathrm{S}_{0}\left(\pi \pi^{*}\right) \rightarrow \mathrm{S}_{2}\left(\pi \pi^{*}\right)$ transition, which is the optically active state populated by the sub-20 fs pump pulse in TAS experiments.

Figure $1 \mathrm{~b}$ shows the steady-state photoluminescence (PL) spectra of buffered, solvated, and $\mathrm{N}_{2}$-pumped 6TG excited by a lamp at $340 \mathrm{~nm}$. We observe a broad band that extends from $350 \mathrm{~nm}$ to $550 \mathrm{~nm}$. Our PL spectrum is in line with the observations of Zou et al. [16]. In contrast, Reichardt et al., did not identify emission from 6TG within the sensitivity of their spectrometer [23]. Ashwood et al., observed two bands for an emission measurement at $77 \mathrm{~K}$ in a tris buffer $7.4 \mathrm{pH}$ matrix: a weak one from $350 \mathrm{~nm}$ to $420 \mathrm{~nm}$ and another intense one from $430 \mathrm{~nm}$ to $550 \mathrm{~nm}$ [43]. The authors assigned the first band (350-420 nm, peaking at $385 \mathrm{~nm}$ ) to the fluorescence emission. The intense band from $430 \mathrm{~nm}$ to $550 \mathrm{~nm}$ was attributed to the phosphorescence emission, which peaks at $480 \mathrm{~nm}$, in reasonable agreement with the vertical excitation energy calculated for the $\mathrm{T}_{1}\left({ }^{3} \pi \pi^{*}\right)$ state at $454 \mathrm{~nm}$ [45] in water. As we show data at room temperature and the sample was pumped with $\mathrm{N}_{2}$ (in order to avoid the formation of singlet oxygen and photoluminescence quenching), we expect an overlap of the contributions from phosphorescence and fluorescence. A decomposition of the PL spectrum reveals two Gaussians centred at $398 \mathrm{~nm}$ (red curve in Figure 1b) and $454 \mathrm{~nm}$ (green curve in Figure 1b). It should be noted that there is a 
gap in the data from 374 to $393 \mathrm{~nm}$ due to a subtraction of a scattering peak from the excitation lamp. Table 1 reports the energies and oscillator strengths of 6TG in vacuum calculated at the MS-CASPT2/ /CASSCF $(14,12)$ / ANO-L level of theory [48-52]. P1, P2, and P3 (coordinates reported in the Supplementary Materials, Table S1) are three single points along the minimum energy path relaxing the $S_{2}\left(\pi \pi^{*}\right)$ state from the Franck-Condon region (Supplementary Materials, Figure S1). Their close adiabatic energies suggest a planar $\mathrm{S}_{2}\left(\pi \pi^{*}\right)$ pseudo-minimum. Since the maximum of the red curve in Figure $1 \mathrm{~b}$ matches the emission wavelength calculated for this pseudo-minimum, we assign it to the fluorescence emission from the $S_{2}\left(\pi \pi^{*}\right)$ state. The peak of the green curve is instead attributed to the phosphorescence from the $\mathrm{T}_{1}\left({ }^{3} \pi \pi^{*}\right)$ state, as also predicted by previous works $[7,43,53]$.

(a)

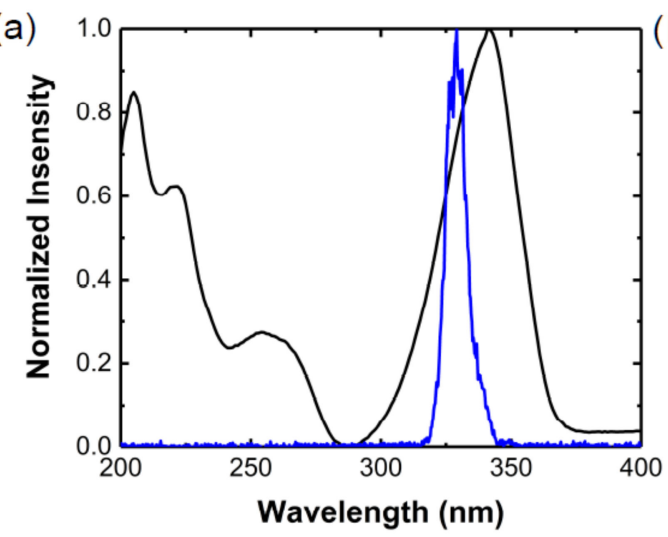

(b)

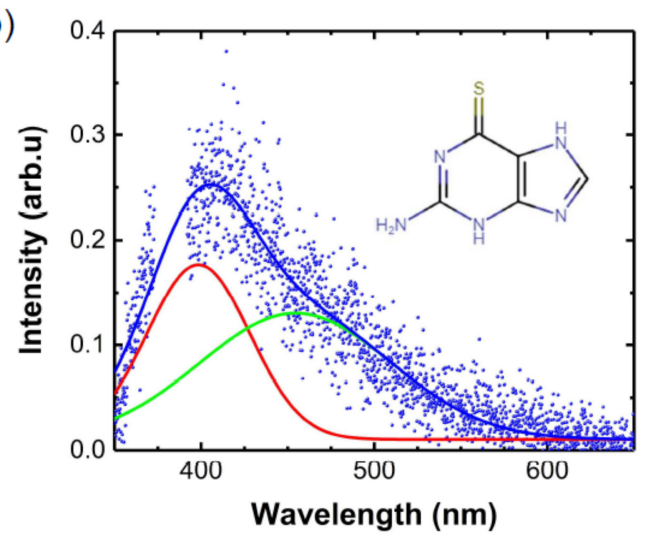

Figure 1. (a) 6TG normalised linear absorption spectrum in a phosphate saline buffer (PSB) solution at pH 7.4 (black curve) and normalised spectrum of the pump pulse employed for the TAS experiments (blue curve). (b) 6TG photoluminescence in a PBS solution (dots) and chemical structure of 6TG (inset). The fit (blue line) is decomposed into two Gaussians representing the contributions from the phosphorescence (green curve) and fluorescence emissions (red curve).

Table 1. Emission energies and oscillator strengths (f) calculated in-vacuum for the $S_{2}\left(\pi \pi^{*}\right)$ state at the Frank-Condon (FC) [43] at three single points $\left(\mathrm{P}_{1}, \mathrm{P}_{2}\right.$, and $\left.\mathrm{P}_{3}\right)$, along the potential energy surface of $S_{2}\left(\pi \pi^{*}\right)$ before reaching the $S_{2}\left(\pi \pi^{*}\right) / S_{1}\left(n \pi^{*}\right) C I$ and for the $S_{1}\left(\pi \pi^{*}\right)$ and $S_{2}\left(n \pi^{*}\right)$ minima [43].

\begin{tabular}{cccc}
\hline State Character & $\begin{array}{c}\text { Vertical Emission Energy } \\
\mathbf{e V}(\mathbf{n m})\end{array}$ & $\begin{array}{c}\text { Adiabatic Emission Energy } \\
\mathbf{e V}(\mathbf{n m})\end{array}$ & $\mathbf{f}$ \\
\hline $\mathrm{FC} \rightarrow \mathrm{S}_{2}\left(\pi \pi^{*}\right)$ & $4.00(311)$ & & 0.187 \\
$\mathrm{P}_{1} \mathrm{~S}_{2}\left(\pi \pi^{*}\right) \rightarrow \mathrm{S}_{0}\left(\pi \pi^{*}\right)$ & $3.16(393)$ & $3.87(320)$ & 0.101 \\
$\mathrm{P}_{2} \mathrm{~S}_{2}\left(\pi \pi^{*}\right) \rightarrow \mathrm{S}_{0}\left(\pi \pi^{*}\right)$ & $3.04(408)$ & $3.87(320)$ & 0.095 \\
$\mathrm{P}_{3} \mathrm{~S}_{2}\left(\pi \pi^{*}\right) \rightarrow \mathrm{S}_{0}\left(\pi \pi^{*}\right)$ & $2.86(434)$ & $3.78(328)$ & 0.061 \\
$\mathrm{~S}_{1}\left(\pi \pi^{*}\right)_{\min } \rightarrow \mathrm{S}_{0}\left(\pi \pi^{*}\right)$ & $2.29(541)$ & $3.79(328)$ & 0.024 \\
$\mathrm{~S}_{1}\left(n \pi^{*}\right)_{\min } \rightarrow \mathrm{S}_{0}\left(\pi \pi^{*}\right)$ & $2.14(580)$ & $3.18(392)$ & 0.001 \\
\hline
\end{tabular}

We performed broadband TAS experiments for 6TG in PBS solution by pumping it with sub-20 fs UV pulses centred at $330 \mathrm{~nm}$ and probing in a broad spectral window from 275 to $630 \mathrm{~nm}$. The acquired TAS map and the transient spectra at selected time delays are displayed in Figure 2a,b, respectively, while Panel c shows the dynamics at selected wavelengths. An intense negative band peaking at $340 \mathrm{~nm}$ is partially superimposed with the lowest-energy band observed in the steady-state linear absorption spectra (Figure 1a), and is therefore assigned to ground state bleaching (GSB). At early times ( $<100 \mathrm{fs})$, we observed a negative band at about $375 \mathrm{~nm}$, which is assigned to stimulated emission (SE) from the $S_{2}\left(\pi \pi^{*}\right)$ state. The peak of the SE band at $375 \mathrm{~nm}$ is in satisfactory agreement with the vertical emission energy calculated from single points at $S_{2}\left(\pi \pi^{*}\right)\left(P_{1}, P_{2}\right.$, and $P_{3}$ in Figure $3 a$ and Table 1) in vacuum. The estimated SE wavelength is also in line with the broadband fluorescence emission shown in Figure 1b, taking into account the experimental 
uncertainties of determining the position of the peaks due to the overlapping signals. The SE band completely decays in less than $80 \mathrm{fs}$, leaving two photoinduced absorption (PA) bands, $\mathrm{PA}_{1}$ peaking at $300 \mathrm{~nm}$ and the broader $\mathrm{PA}_{3}$ peaking about $520 \mathrm{~nm}$.

(a)
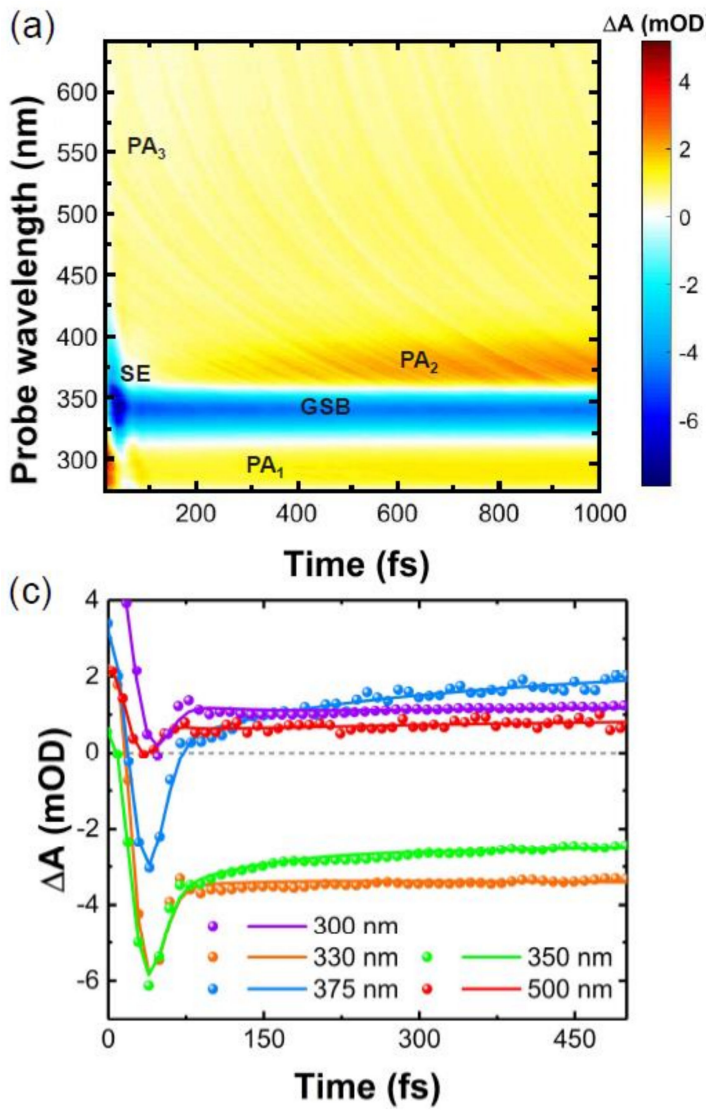

(b)

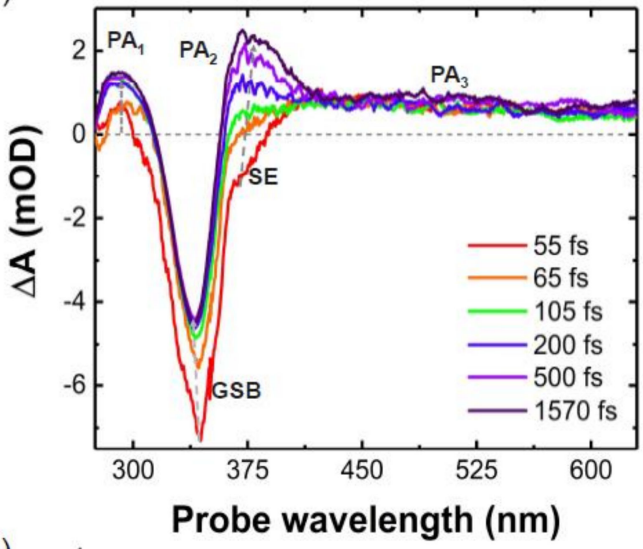

(d)

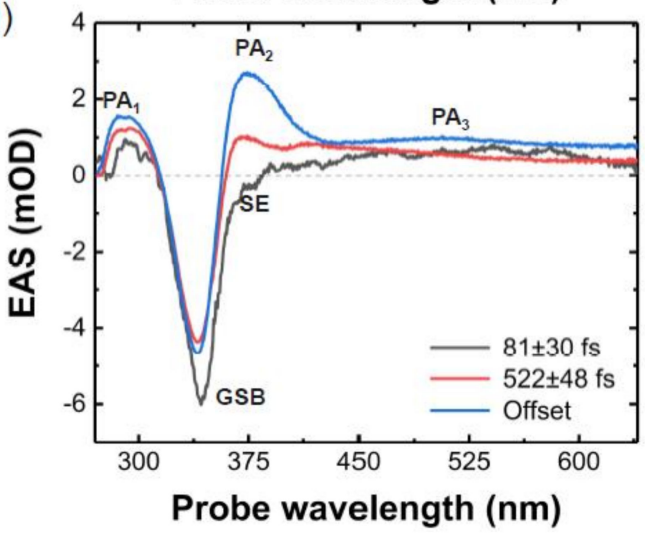

Figure 2. (a) TAS map of solvated 6TG as a function of the pump-probe delay when excited by a 330-nm pulse; (b) transient spectra at the time delays indicated in the legend; (c) dynamics at selected wavelengths during the first $500 \mathrm{fs}$. (d) Evolution associated spectra (EAS) obtained after the analysis of the TAS map shown in Panel (a).

(a)

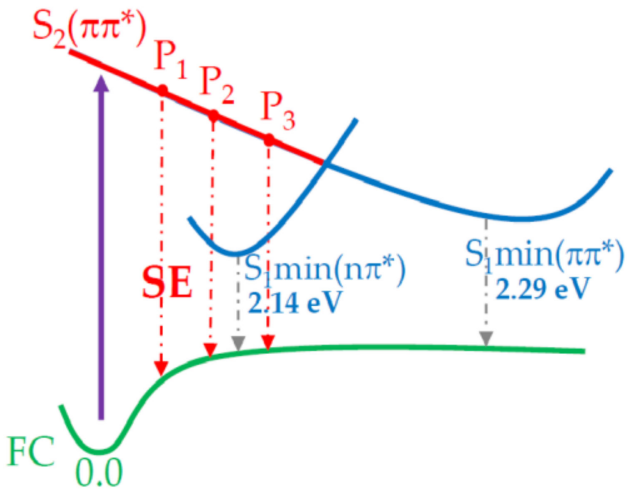

(b)

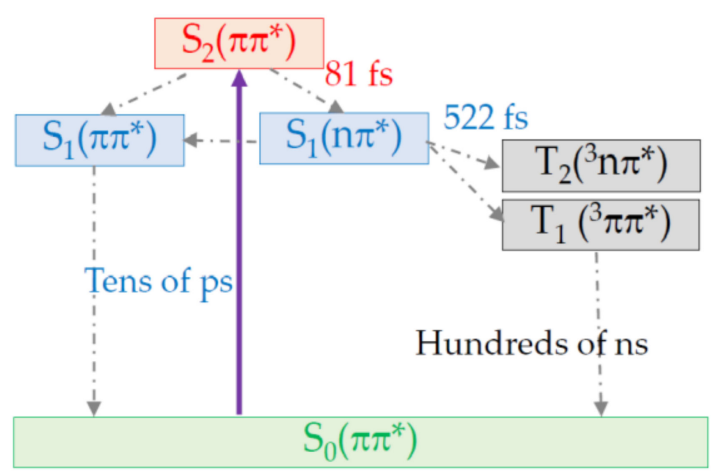

Figure 3. Possible 6TG triplet formation mechanism upon UV photoexcitation. (a) Scheme of the potential energy curves in the vicinity of the $S_{2}\left(\pi \pi^{*}\right) / S_{1}\left(n \pi^{*}\right) C I$ : a UV photon (purple arrow) excites the $S_{2}\left(\pi \pi^{*}\right)$ state (yellow). Relaxation of the wave packet from $S_{2}\left(\pi \pi^{*}\right)$ to $S_{1}\left(n \pi^{*}\right)$ (blue) is mediated by a CI. (b) IC from $S_{2}\left(\pi \pi^{*}\right)$ to $S_{1}\left(n \pi^{*}\right)$ occurs in tens of femtoseconds as predicted in [18]. From here, several decay pathways are open: population of $S_{1}\left(\pi \pi^{*}\right)$, which decays by IC to the ground state in tens of picoseconds [43], and ISC to the triplets in 520 fs from $S_{1}\left(n \pi^{*}\right)$. 
At later times (>200 fs), we observed the rise of another PA band peaking at $\approx 375 \mathrm{~nm}$ $\left(\mathrm{PA}_{2}\right)$, while the $\mathrm{PA}_{3}$ band remained substantially unchanged. Previous TAS measurements with 200 fs of temporal resolution have also shown long-lived PA bands centred at about $390 \mathrm{~nm}$ and $520 \mathrm{~nm}$, which were identified as signatures of the triplet state based on their theoretical calculations $[23,43]$.

To interpret our results, we review the previous computational studies on 6TG. Photoexcitation by the UV pump pulse creates a wave packet in the bright state, $S_{2}\left(\pi \pi^{*}\right)$. Reichardt et al., by combining quantum-chemical calculations and TAS with 200 fs pulses, suggested that for 6TG, most part of the population accesses the triplet manifold directly from the excited state, $S_{2}\left(\pi \pi^{*}\right)$, while a minor fraction decays by IC to the $S_{1}\left(n \pi^{*}\right)$, which, in-turn relaxes non-radiatively to the ground state in tens of picoseconds [23]. Theoretical studies based on MS-CASPT2/ /CASSCF [46] and TD-DFT [43,45] calculations have found two $S_{1}$ minima: one of $n \pi^{*}$ nature and another of $\pi \pi^{*}$ character. They proposed that the population from the $S_{2}\left(\pi \pi^{*}\right)$ state decays via IC in a barrierless fashion in tens of femtoseconds to the $S_{1}\left(n \pi^{*}\right)$, which acts as a doorway to the triplet manifold. The $S_{1}\left(\pi \pi^{*}\right)$ minimum (see Figure $3 \mathrm{a}$ ) enables a CI to the ground state of about $25 \%$ of the population [43] in tens of picoseconds [18]. From the $S_{1}\left(n \pi^{*}\right)$ minimum, there is an efficient population of the $\mathrm{T}_{1}\left(\pi \pi^{*}\right)$ and the $\mathrm{T}_{2}\left(\mathrm{n} \pi^{*}\right)$ triplet states, which were found to be isoenergetic $[18,46]$. Then, the population is trapped in the bright triplet state for hundreds of nanoseconds $[18,43]$.

The evolution-associated spectra (EAS) for each species were obtained by a global fit of the TAS data using a sequential kinetic model (Figure $2 \mathrm{~d}$ ). The best fit was obtained with two time constants ( $\tau_{1}=81 \pm 30 \mathrm{fs}$ and $\left.\tau_{2}=522 \pm 48 \mathrm{fs}\right)$ and an offset. The offset in the global analysis refers to time constants that are beyond our 2 ps temporal observation window (blue curve in Figure 2d). This EAS (blue curve in Figure 2d) peaks at $375 \mathrm{~nm}$, with a broad band extending from 400 to $650 \mathrm{~nm}$. These spectral signatures are typical of the long-lived triplet state, which has a lifetime estimated to be $830 \mathrm{~ns}$ [43]. The $81 \pm 30 \mathrm{fs}$ time constant is reported for the first time in this study (black curve in Figure 2d). Four signatures are distinguishable in the short-lived EAS. The main negative peak at $340 \mathrm{~nm}$ is assigned to the GSB, which is overlapped with the red-shifted negative signal at around $375 \mathrm{~nm}$. The latter is assigned to the SE from the photoexcited state, $S_{2}\left(\pi \pi^{*}\right)$, for the following reasons: (i) it is in satisfactory agreement with the vertical emission energy calculated for the $S_{2}\left(\pi \pi^{*}\right)$ state (Table $1: P_{1}, P_{2}$, and $P_{3}$ single points); (ii) it matches with the broad fluorescence emission maximum at $385 \mathrm{~nm}$ [43], and it lies within the broadband PL (Figure 1b). Therefore, we estimate that the IC from $S_{2}\left(\pi \pi^{*}\right)$ to $S_{1}\left(n \pi^{*}\right)$ occurs on a time scale of $81 \pm 30 \mathrm{fs}$, which is in line with theoretical calculations that predicted IC in about $50 \mathrm{fs}$ [18]. The two PA bands at $300 \mathrm{~nm}$ and from 380 to $650 \mathrm{~nm}$ could be excited-state absorption signals from $S_{2}\left(\pi \pi^{*}\right)$ since they evolve on the same time scale of the SE, but we might not exclude a minor direct channel to the triplet manifold [18]. In addition, due to the planarity of the $S_{2}\left(\pi \pi^{*}\right)$ potential energy surface, there might be some part of the population trapped in the $S_{2}\left(\pi \pi^{*}\right)$, which decays at later times. Higher-level computations including spectroscopic signals of the corresponding electronic states are needed for an unambiguous assignment. The mismatch between $\tau_{1}$ and $\tau_{2}$ and the observation of SE from $S_{2}\left(\pi \pi^{*}\right)$ delivers the experimental confirmation about the involvement of the dark $S_{1}\left(n \pi^{*}\right)$ mediating the ISC process, as suggested by previous theoretical works for 6TG [18,43]. This shows that the $S_{1}\left(n \pi^{*}\right)$ state acts as a doorway to the triplet manifold, as also observed experimentally in some thiopyrimidines [36,39]. The $\tau_{2}$ time constant is assigned to the lifetime of the $S_{1}\left(n \pi^{*}\right)$ state (red curve in Figure $2 d$ ). It is the same value (within the error margin) reported by Ashwood et al., [43] (0.56 $\pm 0.06 \mathrm{ps})$, which was assigned to the formation of the triplet manifold.

Figure 3 summarises the proposed photoexcitation scenario for 6TG. Excitation at $340 \mathrm{~nm}$ generates a wave packet in the $S_{2}\left(\pi \pi^{*}\right)$ state, the signature for which is identified as an SE band with a time constant as fast as $81 \mathrm{fs}$ in the TAS experiments. The CASPT2/ /CASSCF $(14,12) /$ ANO-L calculations of the potential energy surface reveal a planar character of the $S_{2}\left(\pi \pi^{*}\right)$ state before reaching the CI to the $S_{1}$ state, which acts as a 
doorway to access the triplet manifold in $522 \mathrm{fs}$. Our findings therefore provide experimental evidence of the involvement of the intermediate dark singlet state and highlight $\mathrm{S}_{2}\left(\pi \pi^{*}\right) \rightarrow \mathrm{S}_{1}\left(\mathrm{n} \pi^{*}\right) \rightarrow \mathrm{T}_{1}\left(\pi \pi^{*}\right)$ as the major decay pathway in $6 \mathrm{TG}$.

\section{Materials and Methods}

\subsection{Sample Preparation}

6TG was purchased from Sigma-Aldrich (Sigma-Aldrich Chemie GmbH, Taufkirchen, Germany) with $98 \%$ purity. PBS solution was prepared by dissolving $0.15 \mathrm{~g}$ of monosodium phosphate and $0.27 \mathrm{~g}$ of sodium disodium phosphate in $200 \mathrm{~mL}$ of ultrapure water to obtain a pH of 7.4 and a concentration of $16 \mathrm{mM}$. The 6TG in PBS solution was prepared to obtain a maximum absorbance around $1 \mathrm{OD}$ at the central wavelength of the pump beam $(1.4 \mathrm{mM})$.

\subsection{Linear Absorption}

The linear absorption (LA) spectrum of each sample in PBS solution was measured using a JASCO Corp. V-570 (Jacso Inc., Easton, MD, USA) spectrometer at room temperature. The samples were placed in a $1 \mathrm{~mm}$ internal optical-path quartz cuvette. The spectra (Figure 1a) were background-corrected by subtracting the solvent spectrum measured under the same experimental conditions. The LA spectra were collected before and after each TAS experiment to assure that the sample had not degraded during the experiments.

\subsection{Steady-State Photoluminescence}

We acquired the steady-state emission spectra at room temperature using a Cary Eclipse spectrophotometer (Varian Inc., Palo Alto, CA, USA) with a lamp excitation. The spectra were measured at $1000 \mathrm{~V}$ of photomultiplier voltage with excitation and emission slit widths of $5 \mathrm{~nm}$ and averaging times of $0.9 \mathrm{~s}$. The sample concentrations used were about $0.02 \mathrm{mM}$, and the contribution from the solvent solution was subtracted. After preparation, the sample was pumped with $\mathrm{N}_{2}$ to avoid $\mathrm{O}_{2}$ dissolved in the solution during the measurements that could lead to the formation of singlet oxygen and photoluminescence quenching.

\subsection{Transient Absorption Spectroscopy}

TAS measurements were carried out with a home-made setup [54] fed by an $800 \mathrm{~nm}$ Ti:Sapphire laser system (Libra, Coherent, Santa Clara, CA, USA), which delivers $100 \mathrm{fs}$ pulses at a $1 \mathrm{kHz}$ repetition rate. A fraction of the beam seeds a broadband, visible noncollinear optical parametric amplifier (NOPA), which was mixed with the fundamental wave in a $50 \mu \mathrm{m}$-thick Type II $\beta$-barium borate crystal to generate broadband UV pump pulses at $330 \mathrm{~nm}$ [55]. Probe pulses covering the $275-700 \mathrm{~nm}$ spectral range were obtained by white light generation in a $2 \mathrm{~mm}$-thick $\mathrm{CaF}_{2}$ plate. The data were collected separated in two ranges: $\mathrm{UV}(275-340 \mathrm{~nm})$ with thick $\mathrm{CaF}_{2}$ plate pumped at $400 \mathrm{~nm}$ and visible $(330-650 \mathrm{~nm})$ with thick $\mathrm{CaF}_{2}$ plate pumped at $800 \mathrm{~nm}$. The two datasets were merged to obtain the data shown in Figure 2. The setup's instrumental response function is estimated to be 20-30 fs (depending on the probe wavelength), and ultimately limits the precision of the determination of the faster time constant. For the measurements presented in this study, the pump energy was limited to $27 \mathrm{~nJ}$ (leading to a fluence of $340 \mu \mathrm{J} \cdot \mathrm{cm}^{-2}$ ) to avoid sample photodamage and solvated electrons generated by two-photon absorption from the solvent. A flowing jet configuration was employed for the sample that was flown at a typical rate of $40 \mathrm{rpm}$. The experiments were performed using pump and probe beams with parallel polarisations.

\subsection{Global Analysis and Data Processing}

The TAS datasets were subjected to a global analysis using the free software Glotaran [56,57]. A singular-value decomposition was first performed in order to find the number of linearly independent vectors (decay constants) significantly different from the noise. We found three dominant components and three residual components associated 
with the coherent artefact. A nonlinear, least-squares fit was then performed on the TAS map using a sequential kinetic model with three exponential functions. The time-dependent spectrum is thus represented by the function $\psi(\lambda, t)$, and depends on the wavelengths of the probe and the delay between the pump and the probe:

$$
\psi(\lambda, t) \propto \sum_{l=1}^{n c o m p}\left(e^{k l t} * \operatorname{IRF}(t)\right) E A S_{l}(\lambda)
$$

where $k_{l}$ is the decay rate for each component, $\operatorname{IRF}(t)$ is the instrumental response function, and $E A S_{l}(\lambda)$ are the amplitudes of the exponential decays, known as evolution-associated spectra (EAS).

The analysis also takes into account the coherent artefact, the oscillatory time profile of which was modelled by a sequence of exponentials and the dispersion due to the chirp of the probe (modelled by a third-order polynomial).

At least three independent datasets (i.e., recorded on three different days) were used in the analysis, and all uncertainties are reported as twice the standard deviation of the average lifetime. The larger error in the determination of the faster time constant stems from the presence of the coherent artefact, which affects the dynamics in the first $100 \mathrm{fs}$.

\section{Conclusions}

From experimental data obtained by TAS with sub-20 fs pump pulses and broadband probing in a joint UV and visible window, combined with global analysis, we demonstrate the involvement of a dark singlet state $\left(\mathrm{S}_{1}\left(\mathrm{n} \pi^{*}\right)\right)$ in the decay mechanism of $6 \mathrm{TG}$, which acts as a doorway to the triplet manifold. The ultrafast data are supported by theoretical studies and establish that the major decay pathway in 6TG to the triplet manifold is as follows: $S_{2}\left(\pi \pi^{*}\right) \rightarrow S_{1}\left(\mathrm{n} \pi^{*}\right) \rightarrow T_{1}\left(\pi \pi^{*}\right)$.

Supplementary Materials: The following supporting information can be downloaded online, Figure S1: Minimum energy path from which the single points calculations were extracted. CASSCF $(14,12) /$ ANOL level of theory.; Table S1: XYZ coordinates.

Author Contributions: Conceptualization, G.C., C.M. and A.M.d.P.; methodology, D.C.T.-F., C.M. and R.B.-V.; software, L.M.-F.; formal analysis, D.C.T.-F., L.M.-F., A.M.d.P. and R.B.-V.; investigation, D.C.T.-F., G.C., A.M.d.P. and R.B.-V.; writing-original draft preparation, D.C.T.-F. and R.B.-V.; writing-review and editing, G.C., A.M.d.P. and R.B.-V.; visualization, D.C.T.-F.; supervision, C.M., G.C., A.M.d.P. and R.B.-V.; project administration, G.C. and A.M.d.P.; funding acquisition, G.C. All authors have read and agreed to the published version of the manuscript.

Funding: This research was funded by Ministerio de Ciencia e Investigación (grant n. PID2019110091GB-I00) and the European Commission(grant n. 765266, LightDyNAmics).

Institutional Review Board Statement: Not applicable.

Informed Consent Statement: Not applicable.

Data Availability Statement: Data are available from the authors upon reasonable request.

Acknowledgments: D.C.T.F. and A.M.d.P. acknowledge financial support from the funding agencies Fapemig, CNPq, and CAPES. L.M.F. thanks the PID2019-110091GB-I00 funded by the MCIN/AEI/ $10.13039 / 501100011033$ project for financial support and the Centro de Computación Científica UAM (CCC-UAM) for computing time. G.C. acknowledges support from the H2020 Grant Agreement number 765266 (LightDyNAmics).

Conflicts of Interest: The authors declare no conflict of interest.

Sample Availability: Not available. 


\section{References}

1. Hitchings, G.H.; Elion, G.B.; Falco, E.A.; Russell, P.B.; Sherwood, M.B.; VanderWerff, H. Antagonists of nucleic acid derivatives. J. Biol. Chem. 1950, 183, 1-9. [CrossRef]

2. Pollum, M.; Jockusch, S.; Crespo-Hernández, C.E. Increase in the photoreactivity of uracil derivatives by doubling thionation. Phys. Chem. Chem. Phys. 2015, 17, 27851-27861. [CrossRef] [PubMed]

3. Jordheim, L.P.; Durantel, D.; Zoulim, F.; Dumontet, C. Advances in the development of nucleoside and nucleotide analogues for cancer and viral diseases. Nat. Rev. Drug Discov. 2013, 12, 447-464. [CrossRef] [PubMed]

4. Attard, N.R.; Karran, P. UVA photosensitization of thiopurines and skin cancer in organ transplant recipients. Photochem. Photobiol. Sci. 2012, 11, 62-68. [CrossRef]

5. $\quad$ Pridgeon, S.W.; Heer, R.; Taylor, G.A.; Newell, D.R.; O’Toole, K.; Robinson, M.; Xu, Y.Z.; Karran, P.; Boddy, A.V. Thiothymidine combined with UVA as a potential novel therapy for bladder cancer. Br. J. Cancer 2011, 104, 1869-1876. [CrossRef]

6. Arslancan, S.; Martínez-Fernández, L.; Corral, I. Photophysics and photochemistry of canonical nucleobases' thioanalogs: From quantum mechanical studies to time resolved experiments. Molecules 2017, 22, 998. [CrossRef]

7. Ashwood, B.; Pollum, M.; Crespo-Hernández, C.E. Photochemical and Photodynamical Properties of Sulfur-Substituted Nucleic Acid Bases. Photochem. Photobiol. 2019, 95, 33-58. [CrossRef]

8. Nenov, A.; Conti, I.; Borrego-Varillas, R.; Cerullo, G.; Garavelli, M. Linear absorption spectra of solvated thiouracils resolved at the hybrid RASPT2/MM level. Chem. Phys. 2018, 515, 643-653. [CrossRef]

9. Middleton, C.T.; de La Harpe, K.; Su, C.; Law, Y.K.; Crespo-Hernández, C.E.; Kohler, B. DNA Excited-State Dynamics: From Single Bases to the Double Helix. Annu. Rev. Phys. Chem. 2009, 60, 217-239. [CrossRef]

10. Pecourt, J.M.L.; Peon, J.; Kohler, B. Ultrafast internal conversion of electronically excited RNA and DNA nucleosides in water. J. Am. Chem. Soc. 2000, 122, 9348-9349. [CrossRef]

11. Harada, Y.; Okabe, C.; Kobayashi, T.; Suzuki, T.; Ichimura, T.; Nishi, N.; Xu, Y.Z. Ultrafast intersystem crossing of 4-thiothymidine in aqueous solution. J. Phys. Chem. Lett. 2010, 1, 480-484. [CrossRef]

12. Sánchez-Rodríguez, J.A.; Mohamadzade, A.; Mai, S.; Ashwood, B.; Pollum, M.; Marquetand, P.; González, L.; Crespo-Hernández, C.E.; Ullrich, S. 2-Thiouracil intersystem crossing photodynamics studied by wavelength-dependent photoelectron and transient absorption spectroscopies. Phys. Chem. Chem. Phys. 2017, 19, 19756-19766. [CrossRef]

13. Jiang, J.; Zhang, T.-S.; Xue, J.-D.; Zheng, X.; Cui, G.; Fang, W.-H. Short-time dynamics of 2-thiouracil in the light absorbing $\mathrm{S}_{2}\left(\pi \pi^{*}\right)$ state. J. Chem. Phys. 2015, 143, 175103. [CrossRef]

14. Koyama, D.; Milner, M.J.; Orr-Ewing, A.J. Evidence for a Double Well in the First Triplet Excited State of 2-Thiouracil. J. Phys. Chem. B 2017, 121, 9274-9280. [CrossRef]

15. Bai, S.; Barbatti, M. Why Replacing Different Oxygens of Thymine with Sulfur Causes Distinct Absorption and Intersystem Crossing. J. Phys. Chem. A 2016, 120, 6342-6350. [CrossRef]

16. Zou, X.; Dai, X.; Liu, K.; Zhao, H.; Song, D.; Su, H. Photophysical and Photochemical Properties of 4-Thiouracil: Time-Resolved IR Spectroscopy and DFT Studies. J. Phys. Chem. B 2014, 118, 5864-5872. [CrossRef]

17. Gobbo, J.P.; Borin, A.C. 2-Thiouracil deactivation pathways and triplet states population. Comput. Theor. Chem. 2014, 1040, 195-201. [CrossRef]

18. Martínez-Fernández, L.; Corral, I.; Granucci, G.; Persico, M. Competing ultrafast intersystem crossing and internal conversion: A time resolved picture for the deactivation of 6-thioguanine. Chem. Sci. 2014, 5, 1336. [CrossRef]

19. Ruckenbauer, M.; Mai, S.; Marquetand, P.; González, L. Photoelectron spectra of 2-thiouracil, 4-thiouracil, and 2,4-dithiouracil. J. Chem. Phys. 2016, 144, 074303. [CrossRef]

20. Cerullo, G.; Garavelli, M. A novel spectroscopic window on conical intersections in biomolecules. Proc. Natl. Acad. Sci. USA 2020, 117, 26553-26555. [CrossRef]

21. Borrego-Varillas, R.; Nenov, A.; Kabacinski, P.; Conti, I.; Ganzer, L.; Oriana, A.; Delno, I.; Weingart, O.; Manzoni, C.; Rivalta, I.; et al. Tracking excited state decay mechanisms of pyrimidine nucleosides in real time. Nat. Commun. 2021, 12, 7285. [CrossRef] [PubMed]

22. Xie, B.-B.; Wang, Q.; Guo, W.-W.; Cui, G. The excited-state decay mechanism of 2,4-dithiothymine in the gas phase, microsolvated surroundings, and aqueous solution. Phys. Chem. Chem. Phys. 2017, 19, 7689-7698. [CrossRef] [PubMed]

23. Reichardt, C.; Guo, C.; Crespo-Hernández, C.E. Excited-state dynamics in 6-thioguanosine from the femtosecond to microsecond time scale. J. Phys. Chem. B 2011, 115, 3263-3270. [CrossRef] [PubMed]

24. Reichardt, C.; Crespo-Hernaíndez, C.E. Room-temperature phosphorescence of the DNA monomer analogue 4-thiothymidine in aqueous solutions after UVA excitation. J. Phys. Chem. Lett. 2010, 1, 2239-2243. [CrossRef]

25. Pollum, M.; Jockusch, S.; Crespo-hernández, C.E. 2,4-Dithiothymine as a Potent UVA Chemotherapeutic Agent. J. Am. Chem. Soc. 2014, 136, 17930-17933. [CrossRef] [PubMed]

26. Sismour, A.M. The use of thymidine analogs to improve the replication of an extra DNA base pair: A synthetic biological system Nucleic Acids Res. 2005, 33, 5640-5646. [CrossRef]

27. Heuberger, B.D.; Pal, A.; Del Frate, F.; Topkar, V.V.; Szostak, J.W. Replacing Uridine with 2-Thiouridine Enhances the Rate and Fidelity of Nonenzymatic RNA Primer Extension. J. Am. Chem. Soc. 2015, 137, 2769-2775. [CrossRef]

28. Favre, A.; Moreno, G.; Blondel, M.O.; Kliber, J.; Vinzens, F.; Salet, C. 4-thiouridine photosensitized RNA-protein crosslinking in mammalian cells. Biochem. Biophys. Res. Commun. 1986, 141, 847-854. [CrossRef] 
29. Pollum, M.; Lam, M.; Jockusch, S.; Crespo-Hernández, C.E. Dithionated Nucleobases as Effective Photodynamic Agents against Human Epidermoid Carcinoma Cells. ChemMedChem 2018, 13, 1044-1050. [CrossRef]

30. Harris, M.; Cote, H.; Ochoa, C.; Allavena, C.; Negredo, E.; Cahn, P.; Zala, C.; Raffi, F. A Randomized, Open-Label Study of a Nucleoside Analogue Reverse Transcriptase Inhibitor-Sparing Regimen in Antiretroviral-Naive HIV-Infected Patients. J. Acquir. Immune Defic. Syndr. 2009, 50, 339-340. [CrossRef]

31. Meisenheimer, K.M.; Koch, T.H. Photocross-Linking of Nucleic Acids to Associated Proteins. Crit. Rev. Biochem. Mol. Biol. 1997, 32, 101-140. [CrossRef]

32. Reelfs, O.; Karran, P.; Young, A.R. 4-thiothymidine sensitization of DNA to UVA offers potential for a novel photochemotherapy. Photochem. Photobiol. Sci. 2012, 11, 148-154. [CrossRef]

33. Massey, A.; Xu, Y.Z.; Karran, P. Photoactivation of DNA thiobases as a potential novel therapeutic option. Curr. Biol. 2001, 11, 1142-1146. [CrossRef]

34. Martínez-Fernández, L.; Granucci, G.; Pollum, M.; Crespo-Hernández, C.E.; Persico, M.; Corral, I. Decoding the Molecular Basis for the Population Mechanism of the Triplet Phototoxic Precursors in UVA Light-Activated Pyrimidine Anticancer Drugs. Chem.-A Eur. J. 2017, 23, 2619-2627. [CrossRef]

35. Mai, S.; Marquetand, P.; González, L. Intersystem Crossing Pathways in the Noncanonical Nucleobase 2-Thiouracil: A TimeDependent Picture. J. Phys. Chem. Lett. 2016, 7, 1978-1983. [CrossRef]

36. Borrego-Varillas, R.; Teles-Ferreira, D.C.; Nenov, A.; Conti, I.; Ganzer, L.; Manzoni, C.; Garavelli, M.; de Paula, A.M.; Cerullo, G. Observation of the Sub-100 Femtosecond Population of a Dark State in a Thiobase Mediating Intersystem Crossing. J. Am. Chem. Soc. 2018, 140, 16087-16093. [CrossRef]

37. Pollum, M.; Crespo-Hernández, C.E. Communication: The dark singlet state as a doorway state in the ultrafast and efficient intersystem crossing dynamics in 2-thiothymine and 2-thiouracil. J. Chem. Phys. 2014, 140, 071101. [CrossRef]

38. Cui, G.; Fang, W.-H. State-specific heavy-atom effect on intersystem crossing processes in 2-thiothymine: A potential photodynamic therapy photosensitizer. J. Chem. Phys. 2013, 138, 044315. [CrossRef]

39. Teles-Ferreira, D.C.; Conti, I.; Borrego-Varillas, R.; Nenov, A.; Van Stokkum, I.H.M.; Ganzer, L.; Manzoni, C.; de Paula, A.M.; Cerullo, G.; Garavelli, M. A Unified Experimental/Theoretical Description of the Ultrafast Photophysics of Single and Double Thionated Uracils. Chem.-A Eur. J. 2020, 26, 336-343. [CrossRef]

40. Siouri, F.M.; Boldissar, S.; Berenbeim, J.A.; de Vries, M.S. Excited State Dynamics of 6-Thioguanine. J. Phys. Chem. A 2017, 121, 5257-5266. [CrossRef] [PubMed]

41. Martinez-Fernandez, L.; Fahleson, T.; Norman, P.; Santoro, F.; Coriani, S.; Improta, R. Optical absorption and magnetic circular dichroism spectra of thiouracils: A quantum mechanical study in solution. Photochem. Photobiol. Sci. 2017, 16, 1415-1423. [CrossRef] [PubMed]

42. Pollum, M.; Ortiz-Rodríguez, L.A.; Jockusch, S.; Crespo-Hernández, C.E. The Triplet State of 6-thio-2'-deoxyguanosine: Intrinsic Properties and Reactivity toward Molecular Oxygen. Photochem. Photobiol. 2016, 92, 286-292. [CrossRef] [PubMed]

43. Ashwood, B.; Jockusch, S.; Crespo-Hernández, C.E. Excited-state dynamics of the thiopurine prodrug 6-thioguanine: Can N9-glycosylation affect its phototoxic activity? Molecules 2017, 22, 379. [CrossRef] [PubMed]

44. Farrell, K.M.; Brister, M.M.; Pittelkow, M.; Sølling, T.I. Heavy-Atom-Substituted Nucleobases in Photodynamic Applications: Substitution of Sulfur with Selenium in 6-Thioguanine Induces a Remarkable Increase in the Rate of Triplet Decay in 6-Selenoguanine. J. Am. Chem. Soc. 2018, 140, 11214-11218. [CrossRef]

45. Pirillo, J.; Mazzone, G.; Russo, N.; Bertini, L. Photophysical Properties of S, Se and Te-Substituted Deoxyguanosines: Insight into Their Ability to Act as Chemotherapeutic Agents. J. Chem. Inf. Modeling 2017, 57, 234-242. [CrossRef]

46. Martínez-Fernández, L.; González, L.; Corral, I. An ab initio mechanism for efficient population of triplet states in cytotoxic sulfur substituted DNA bases: The case of 6-thioguanine. Chem. Commun. 2012, 48, 2134-2136. [CrossRef]

47. Santhosh, C.; Mishra, P.C. Electronic structures and spectra of 6-mercaptopurine and 6-thioguanine. Spectrochim. Acta Part A Mol. Spectrosc. 1993, 49, 985-993. [CrossRef]

48. Andersson, K.; Malmqvist, P.Å.; Roos, B.O. Second-order perturbation theory with a complete active space self-consistent field reference function. J. Chem. Phys. 1992, 96, 1218-1226. [CrossRef]

49. Roos, B.O.; Andersson, K. Multiconfigurational perturbation theory with level shift-The $\mathrm{Cr}_{2}$ potential revisited. Chem. Phys. Lett. 1995, 245, 215-223. [CrossRef]

50. Finley, J.; Malmqvist, P.Å.; Roos, B.O.; Serrano-Andrés, L. The multi-state CASPT2 method. Chem. Phys. Lett. 1998, 288, 299-306. [CrossRef]

51. Pou-Amérigo, R.; Merchán, M.; Nebot-Gil, I.; Widmark, P.O.; Roos, B.O. Density matrix averaged atomic natural orbital (ANO) basis sets for correlated molecular wave functions-III. First row transition metal atoms. Theor. Chim. Acta 1995, 92, 149-181. [CrossRef]

52. Fernández Galván, I.; Vacher, M.; Alavi, A.; Angeli, C.; Aquilante, F.; Autschbach, J.; Bao, J.J.; Bokarev, S.I.; Bogdanov, N.A.; Carlson, R.K.; et al. OpenMolcas: From Source Code to Insight. J. Chem. Theory Comput. 2019, 15, 5925-5964. [CrossRef]

53. Zou, X.; Zhao, H.; Yu, Y.; Su, H. Formation of guanine-6-sulfonate from 6-thioguanine and singlet oxygen: A combined theoretical and experimental study. J. Am. Chem. Soc. 2013, 135, 4509-4515. [CrossRef]

54. Borrego-Varillas, R.; Ganzer, L.; Cerullo, G.; Manzoni, C. Ultraviolet Transient Absorption Spectrometer with Sub-20-fs Time Resolution. Appl. Sci. 2018, 8, 989. [CrossRef] 
55. Varillas, R.B.; Candeo, A.; Viola, D.; Garavelli, M.; De Silvestri, S.; Cerullo, G.; Manzoni, C.; De Silvestri, S.; Cerullo, G.; Manzoni, C.; et al. Microjoule-level, tunable sub-10 fs UV pulses by broadband sum-frequency generation. Opt. Lett. 2014, 39, 3849-3852. [CrossRef]

56. Snellenburg, J.J.; Laptenok, S.P.; Seger, R.; Mullen, K.M.; van Stokkum, I.H.M. Glotaran: A Java-Based Graphical User Interface for the R Package TIMP. J. Stat. Softw. 2012, 49, 1-22. [CrossRef]

57. Van Stokkum, I.H.M.; Larsen, D.S.; Van Grondelle, R. Global and target analysis of time-resolved spectra. Biochim. Biophys. Acta-Bioenerg. 2004, 1657, 82-104. [CrossRef] 